\title{
Formulation and Characterization of pH Induced in situ Gels Containing Sulfacetamide Sodium for Ocular Drug Delivery: A Combination of Carbopol ${ }^{\circledR} /$ HPMC Polymer
}

\author{
Ravi Sheshala, ${ }^{1,2 *}$, Ng Jun Ming ${ }^{1}$, Yong Yee Kok, Thakur Raghu Raj Singh³, Kamal Dua, ${ }^{4,5}$ \\ ${ }^{1}$ School of Pharmacy, International Medical University, Bukit Jalil, Kuala Lumpur, MALAYSIA. \\ ${ }^{2}$ Department of Pharmaceutics, Faculty of Pharmacy, Universiti Teknologi MARA Selangor, Puncak Alam Campus, 42300 Bandar \\ Puncak Alam, Kuala Selangor, MALAYSIA. \\ ${ }^{3}$ School of Pharmacy, Queen's University Belfast, Belfast, BT9 7BL, UNITED KINGDOM. \\ ${ }^{4}$ Discipline of Pharmacy, Graduate School of Health, University Technology Sydney, Ultimo, New South Wales, AUSTRALIA. \\ ${ }^{5}$ Priority Research Centre for Healthy Lungs, Hunter Medical Research Institute (HMRI) and School of Biomedical Sciences and \\ Pharmacy, University of Newcastle, Callaghan, NSW, AUSTRALIA.
}

\begin{abstract}
Introduction: Topical delivery of eye drops which currently accounts to $90 \%$ of available ocular dosage forms are ideal for the treatment of eye diseases but having limitations of poor therapeutic response and low bioavailability. Objectives: The objectives of present research was to develop and characterize sustained release in situ ocular gels containing sufacetamide sodium using $\mathrm{pH}$ induced gelling polymers for improved therapeutic response and patient compliance. Methods: In situ gel formulations prepared by dispersion method using $\mathrm{Carbopol}^{\circ} 940 / \mathrm{Carbopol}^{\circ} 934$ alone or in combination with hydroxypropyl methylcellulose (HPMC E4M). Formultaions were evaluated for appearance, $\mathrm{pH}$, viscosity, gelling capacity, drug content and in vitro drug release. The optimized formulation was assessed for sterility and antimicrobial efficacy using disk diffusion technique in comparison to commercial eye drops (Albucid $10 \%$ ). Results: The appearance of in situ gels were clear and free flowing in nature however, a viscous clear solution with no flow was produced for formulations consisting of $0.8 \% \mathrm{w} / \mathrm{v}$ Carbopol $^{\circ} 940 /$ Carbopol $^{\circ} 934$ and $2 \% \mathrm{w} / \mathrm{v}$ HPMC E4M. pH of all the formulations was within the range of 5.9 to 6.7. In situ gels with $\mathrm{Carbopol}^{\circ} 940$ demonstrated higher viscosity compared to $\mathrm{Carbopol}^{\circ} 934$ and drug release was sustained over a period of 8 $\mathrm{hr}$. The selected formulation containing $0.8 \% \mathrm{w} / \mathrm{v}$ Carbopol $^{\circ} 940$ and $1.5 \% \mathrm{w} / \mathrm{v} \mathrm{HPMC}$ E4M passed sterility test and demonstrated similar antimicrobial efficiency compared to

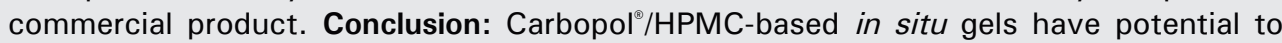
improve patient's compliance by reducing the dosing frequency and could be a viable alternative to commercial product.
\end{abstract}

Key words: In situ gel, Ocular, Sulfacetamide sodium, Carbopol $/ \mathrm{HPMC}$, In-vitro release, Antimicrobial efficacy.

\section{INTRODUCTION}

Ocular drug delivery is one of the most interesting and challenging areas of pharmaceutical research. Topical delivery of eye drops which currently accounts for $90 \%$ of accessible ocular formulations is an ideal treatment for ocular diseases especially when the drug needs to produce a local- ized action. However, topical delivery is not without problems such as the poor bioavailability and therapeutic response. These challenges are attributable to the rapid precorneal elimination due to tear secretion, non-productive absorption due to the biological barrier for drug penetration, absorp-
Submission Date: 23-10-2018; Revision Date: 30-11-2018; Accepted Date: 04-09-2019

DOI: 10.5530/ijper.53.4.127 Correspondence: Dr. Ravi Sheshala, Department of Pharmaceutics, Faculty of Pharmacy, Universiti Teknologi MARA Selangor, Puncak Alam Campus-42300, Puncak Alam, Kuala Selangor, Malaysia.

Phone: +60-03-32584836 E-mail: ravisheshala@uitm. edu.my

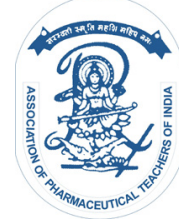

www.ijper.org 
tion into the gastrointestinal tract due to drainage through nasal lacrimal duct and poor patient's compliance due to increasing number of instillations and difficulty in self-administration. ${ }^{1-4}$ Thus, the concept of polymeric in situ gel forming system was introduced to alleviate these problems. In situ gels are free flowing solutions at room temperature that undergo phase transition from solution-gel (sol-gel) as a result of exposure to physiological temperature, $\mathrm{pH}$ or ionic compositions of lacrimal fluid. ${ }^{5-7}$ The gel formed in the eye effectively prevents the rapid drainage of instilled drug from ocular site, improves the retention time of dosage form at the site of administration and sustains the drug release for a prolonged period of time. It aids to reduce the dosing frequency and to improve the therapeutic efficiency of drug. Furthermore, systemic side effects would also be reduced due to less systemic absorption. Therefore, it enhances patient's compliance and convienence. ${ }^{5}$

Carbopol $^{\circledR}$ is a water soluble $\mathrm{pH}$ dependent in situ polymer. The formulations comprising of $\mathrm{Carbopol}^{\circledR}$ polymer remained as solution at acidic $\mathrm{pH}$ and forms a low viscosity gel when $\mathrm{pH}$ raised to alkaline. The $\mathrm{pH}$ difference between the formulations containing Carbopol $^{\circledR}$ and human tear fluid makes the sol-gel transition occurs almost instantly. Besides, Carbopol ${ }^{\circledR}$ has an excellent mucoadhesive property. Therefore, the polymer is responsible to increase the contact time of a drug in the eye by adhering to the ocular surface and thereby release the drug in a controlled fashion. However, acidic nature of $\mathrm{Carbopol}^{\circledR}$ may cause damage to surface of eye before being neutralized by the lacrimal fluid. Thus, HPMC, a viscosity enhancing polymer is usually added to Carbopol ${ }^{\mathbb{Q}}$ contained formulations to overcome this problem, which resulted in $\mathrm{pH}$ induced polymeric mixture (Carbopol $\left.{ }^{\circledR} / \mathrm{HPMC}\right)$. This polymeric mixture is in liquid state at it's native formulated $\mathrm{pH} 4$ to 6 at room temperature but rapid transition into gel phase occurs at the $\mathrm{pH}$ of tear fluid ( $\mathrm{pH} 7.4)$. $38-10^{3}$ To date, many of the ocular in situ forming gels have been investigated with a combination of $\mathrm{Carbopol}^{\circledR}$ and cellulose derivatives. ${ }^{8,11-13}$ In addition, these two polymers are already listed in the FDA's Inactive Ingredient Guide (IIG) and widely used commercially for various drug applications including topical ophthalmic solutions. ${ }^{14-16}$ Therefore, these polymers are considered to be safe to use.

Sulfacetamide sodium is a sulfonamide with antibacterial activity. It is commerically available in the dosage forms of lotion and solution. The ocular dosage form is commonly used to treat conjunctivitis and other superficial ocular infections caused by susceptible micro-organisms such as Staphylococcus aureus, Escherichia coli, Streptococcus pneumoniae, Klebsiella species and Enterobacter species. The major drawback of commercial eye drops, however, is the dosing frequency, which has to be administered 1 to 2 drops every 2 to $3 \mathrm{hr}$ ( 8 to 12 times in a day). ${ }^{17}$ This high frequency of sulfacetamide sodium eye drops administration is associated with poor patient compliance and convenience. To overcome all the aforementioned constrains offered by eye drops, an alternative apporach of in situ gelling system with a combination of Carbopol ${ }^{\circledR}$ and HPMC was investigated as a vehicle for the formulation of sustained release smart eye drops containing sulfacetamide sodium. Furthermore, to the best of our knowledge, till date there is no published literature on the formulation of in situ gels containing sulfacetamide sodium.

\section{MATERIALS AND METHODS}

\section{Materials}

Sulfacetamide sodium, methyl paraben and propyl paraben were purchased from Sigma-Aldrich Chemical Co. (St. Louis, MO, USA). Carbopol ${ }^{\circledR}$ polymers $\left(\right.$ Carbopol $^{\circledR}$ 940 and $\mathrm{Carbopol}^{\circledR}$ 934) were purchased from DCM personal care Sdn Bhd (Selangor, Malaysia). HPMC E4M was obtained as a gift sample from Dow Chemical Co. (Illinois, USA). Muller Hinton agar medium and fluid thioglycolate medium were purchased from Becton Dickinson Sdn Bhd (Selangor, Malaysia). All other solvents and chemicals used were of analytical grade.

\section{Preparation of in situ gel formulations}

The composition of in situ gel formulations containing sulfacetamide sodium is shown in Table 1. In situ gel formulations containing different concentratios of Carbopol $^{\circledR} 940 /$ Carbopol $^{\circledR} 934$ in combination with HPMC E4M were prepared by dispersion method. ${ }^{18-20}$ Briefly, about $75 \mathrm{~mL}$ distilled water was preheated to $70^{\circ} \mathrm{C}$ to dissolve methyl and propylparaben and then sodium chloride $(\mathrm{NaCl}), \mathrm{HPMC}$ and $\mathrm{Carbopol}^{\circledR}$ were incorporated into the solution. The mixture was left at room tempeature overnight to allow the polymer to hydrate. Sulfacetamide sodium was dissolved in $25 \mathrm{~mL}$ distilled water separately. It was added into above polymeric solution and stirred until a uniform solution was obtained. The final product was filled into sterile amber colour bottles and sterilized in autoclave at $121^{\circ} \mathrm{C}$ for $15 \mathrm{~min}$. The prepared formulations were stored in refrigerator at $4^{\circ} \mathrm{C}$ until further use.

\section{Evaluation of in situ gel formulations}

\section{Appearance and clarity, $\mathrm{pH}$ and drug content}

The appearance and clarity of formulations were observed visually against a black and white background for presence of any particulate matter in the formulation. ${ }^{4}$ 


\begin{tabular}{|c|c|c|c|c|c|c|c|c|c|c|}
\hline Ingredients $(\% \mathrm{w} / \mathrm{v})$ & F1 & F2 & F3 & F4 & F5 & F6 & F7 & F8 & F9 & F10 \\
\hline Sulfacetamide sodium & 10 & 10 & 10 & 10 & 10 & 10 & 10 & 10 & 10 & 10 \\
\hline Carbopol $^{\circledR} 940$ & 0.3 & 0.5 & 0.8 & 0.8 & 0.8 & 0.8 & - & - & - & - \\
\hline Carbopol $^{\circledR} 934$ & - & - & - & - & - & - & 0.6 & 0.8 & 0.8 & 0.8 \\
\hline HPMC E4M & 0.6 & 0.6 & 0.6 & 1.0 & 1.5 & 2.0 & 1.0 & 1.0 & 1.5 & 2.0 \\
\hline Sodium chloride & 0.9 & 0.9 & 0.9 & 0.9 & 0.9 & 0.9 & 0.9 & 0.9 & 0.9 & 0.9 \\
\hline Methyl paraben & 0.1 & 0.1 & 0.1 & 0.1 & 0.1 & 0.1 & 0.1 & 0.1 & 0.1 & 0.1 \\
\hline Propyl paraben & 0.05 & 0.05 & 0.05 & 0.05 & 0.05 & 0.05 & 0.05 & 0.05 & 0.05 & 0.05 \\
\hline Water qs ad & 100 & 100 & 100 & 100 & 100 & 100 & 100 & 100 & 100 & 100 \\
\hline
\end{tabular}

The $\mathrm{pH}$ of formulations was determined using a digital pH meter (METTLER Toledo, S220 SevenCompact ${ }^{\mathrm{TM}}$ $\mathrm{pH} / \mathrm{Ion})$ to ensure that the formulations do not cause any ocular irritation to the patient upon administration. To determine the drug content in the formulations, $1 \mathrm{~mL}$ of the formulation was dissolved in $100 \mathrm{~mL}$ simulated tear fluid (STF, $\mathrm{pH}$ 7.4) and further diluted with same medium to measure the absorbance using UV-Visible spectrophotometer at a wavelength of $257 \mathrm{~nm}$. The composition of STF $\mathrm{pH} 7.4$ is as follows: $0.670 \mathrm{~g}$ of $\mathrm{NaCl}, 0.200 \mathrm{~g}$ of $\mathrm{NaHCO}_{3}, 0.008 \mathrm{~g}$ of $\mathrm{CaCl}_{2} \cdot{ }_{2} \mathrm{H}_{2} \mathrm{O}$ and distilled water up to $100 \mathrm{~mL}$. The samples were measured in triplicate.

\section{Viscosity}

The viscosity of the formulations was determined using DV-III ULTRA Programmable Rheometer (Model LV) using a spindle-SC4-18 which is immersed in a formulation to be tested. The spindle speed was set at $20 \mathrm{rpm}$ and and the temperature was maintained at $25^{\circ} \mathrm{C}$. The viscosity values were calculated using Bingham's calculation. The samples were measured in triplicate to ensure that the developed formulations having suitable viscosity to avoid the rapid pre-corneal elimination of drug.

\section{Gelling capacity}

The prepared formulations were evaluated for gelling capacity in order to ascertain the composition suitable for use as in situ gelling system. The gelling capacity was determined by placing $1 \mathrm{~mL}$ of prepared formulation into a test tube contatining $5 \mathrm{~mL}$ of STF pH 7.4 at $37^{\circ} \mathrm{C}$. The time taken to transition of solution to gel and the time taken for the formed gel to dissolve were visually observed. The congo red dye was added into the formulation to give visualised appearance of formed gel. The gelling capacity of the formulations was graded in four groups such as no gelation (-), poor $(+)$, good $(++)$ and excellent $(+++)$ based on the gelation time and time period for which the formed gel remains as such. ${ }^{21,22}$

\section{In-vitro drug release studies}

In-vitro drug release studies were conducted using dialysis membrane method in triplicate. ${ }^{23}$ Firstly, the dialysis membrane (molecular weight cut-off 12000$14000 \mathrm{Da}$ ) which was soaked overnight in the dissolution medium was opened as a bag and tied at one-end. About $1 \mathrm{~mL}$ of the selected formulation comprising a combination of $\mathrm{Carbopol}^{\circledR} / \mathrm{HPMC}$ was placed into one-end tied dialysis bag and then added $0.5 \mathrm{~mL}$ of STF $\mathrm{pH} 7.4$ to simulate the gel formation in the eye after instillation of in situ gel preparation. Thereafter, second-end of dialysis bag was also tied properly and immersed in a beaker containing $100 \mathrm{~mL}$ of STF $\mathrm{pH} 7.4$ which simulates the tear fluid and it's $\mathrm{pH}$. The beaker was placed in a shaker water bath which was set at $50 \mathrm{rpm}$ and $37^{\circ} \mathrm{C}$. About $2 \mathrm{~mL}$ of the sample was withdrawn at $0.5,1,2$, $3,4,6$ and $8 \mathrm{~h}$ and replaced the same amount of freshly prepared STF to maintain the sink conditions. The samples were analyzed using UV-Visible spectrophotometer at $257 \mathrm{~nm}$ using STF as a blank.

The resultant release data was fitted into different release kinetic models i.e. zero order, first order, Higuchi, Hixon-crowell and Korsemeyer-peppas in order to determine the drug release pattern and release mechanism. The time taken to release $50 \%$ of the drug $\left(\mathrm{T}_{50 \%}\right)$ was calculated and treated statistically using one-way analysis of variance (ANOVA). When there was a statistically significant difference, a post hoc Tukey's HSD (honestly significant difference) test was performed. A value of $p<0.05$ was considered as statistically significant.

\section{Sterility testing}

Ocular products has to be sterile, thus it is necessary to carry out sterility testing. The selected formulation was aseptically transferred into sterile fluid thioglycolate medium and incubated for not less than 14 days at $35^{\circ} \mathrm{C}$ 
to evaluate the growth of bacteria. The sterility of the formulation was visually determined by the clarity of the medium until 14 days. ${ }^{24-27}$

\section{Antimicrobial efficacy studies}

The antimicrobial efficacy studies were carried out by disk diffusion technique to ascertain the biological activity of the selected formulation. The conventional eye drops (Albucid ${ }^{\circledR} 10 \%$ ) served as a reference and selected formulation was placed into cups bored into sterile Muller Hinton Agar medium previously seeded with Staphylococcus aureus, Escherichia coli and klabsiella pneumoniae microorganisms. The plates were incubated for $24 \mathrm{~h}$ at $37^{\circ} \mathrm{C}$ and the zone of inhibition was measured in $\mathrm{mm}$. Each formulation was tested in triplicate. The results were treated statistically using Independent samples $t$-test. A value of $p<0.05$ was considered as statistically significant.

\section{RESULTS AND DISCUSSION}

The obtained results of appearnace and clarity, $\mathrm{pH}$, drug content, viscosity and gelling capacity for prepared in situ gel formulations are shown in Table 2.

\section{Appearance and clarity, $\mathrm{pH}$ and drug content}

All the prepared formulations were found to be transparent and clear excluding the formulations consisting of $0.8 \% \mathrm{w} / \mathrm{v}$ of $\mathrm{Carbopol}^{\circledR} 940$ (F6) and $\mathrm{Carbopol}^{\circledR}$ 934 (F10) in combination with HPMC (2\% w/v). These two formulations were found to be highly clear viscous solutions with no flow which might be due to high concentration of both Carbopol ${ }^{\circledR}$ and HPMC. Hence, formulations were not prepared with further increase in the concentrations of both polymers. The $\mathrm{pH}$ of formulations were found to be in the range of 5.97 to 6.71 . The combination of water soluble polymeric system i.e. $\mathrm{Carbopol}^{\circledR} / \mathrm{HPMC}$ aided to reduce the acidity of the solution. The $\mathrm{pH}$ of formulation would raises instantly to $\mathrm{pH} 7.4$ (an ideal ocular $\mathrm{pH}$ ) after instillation into eye due to $\mathrm{pH}$ of lacrimal secretion. Thus, the formulations were considered to be suitable for opthalmic administration and may not cause any irritation to ocular tissues upon administration. ${ }^{2,28}$ The dug content of all the formulations was found to be in the acceptable range of $98.63 \%$ to $99.63 \%$ and results demonstrated the uniform distribution of drug in the prepared formulations.

\section{Viscosity}

Viscosity of formulations is an important factor in determining residence time of drug in the eye as the low viscosity solutions may drain faster after insitillation into eye and high viscosity solutions would be difficult for instillation and also have poor spreadability in the eye. Viscosity of all the formulations was found to be in the range of 64.8 to $1857 \mathrm{cP}$. The viscosity was directly dependent on the polymeric content of the formulations and increase in the polymer concentration caused to increase in viscosity of the formulations. Formulations consisting of Carbopol ${ }^{\circledR} 940$ showed higher viscosity compared to Carbopol ${ }^{\circledR}$ 934. It might be due to differences in their crosslinking density as Carbopol ${ }^{\mathbb{P}} 940$ has high crosslinking density and Carbopol ${ }^{\circledR} 934$ has low

\begin{tabular}{|c|c|c|c|c|c|}
\hline \multicolumn{5}{|c|}{ Table 2: Results of physicochemical characterization of in situ gel formulations. } \\
\hline Formulation & Clarity & pH & $\begin{array}{c}\text { Drug content } \\
\text { (\%) }\end{array}$ & Viscosity (cP) & $\begin{array}{c}\text { Gelling } \\
\text { capacity }^{*}\end{array}$ \\
\hline F1 & Transparent and Clear & 6.71 & $99.13 \pm 0.35$ & $64.80 \pm 0.71$ & - \\
\hline F2 & Transparent and Clear & 6.27 & $99.07 \pm 0.51$ & $86.05 \pm 0.64$ & + \\
\hline F3 & Transparent and Clear & 5.97 & $99.27 \pm 0.15$ & $259.20 \pm 7.07$ & ++ \\
\hline F4 & Transparent and Clear & 6.03 & $98.63 \pm 0.23$ & $1023.00 \pm 63.64$ & ++ \\
\hline F5 & Transparent and Clear & 6.02 & $98.67 \pm 0.21$ & $1209.00 \pm 28.28$ & +++ \\
\hline F6 & Clear and Viscous & 6.27 & $98.87 \pm 0.32$ & $1857.00 \pm 82.02$ & NS $^{* *}$ \\
\hline F7 & Transparent and Clear & 6.20 & $99.63 \pm 0.15$ & $685.10 \pm 12.59$ & + \\
\hline F8 & Transparent and Clear & 6.19 & $98.90 \pm 0.20$ & $726.50 \pm 0.00$ & ++ \\
\hline F9 & Transparent and Clear & 6.08 & $99.00 \pm 0.40$ & $1063.75 \pm 7.14$ & ++ \\
\hline F10 & Clear and Viscous & 6.19 & $98.80 \pm 0.20$ & $1572.50 \pm 68.59$ & NS $^{* *}$ \\
\hline
\end{tabular}

*"-" no gelation, "+" gelation immediate but dissolves rapidly (1-2 h), "++" gelation immediate and remain for few h (3-4 h), "+++" stiff gel is formed immediately and remain for extended period (more than 6-8 $\mathrm{h}$ ).

${ }^{* *}$ Not Studied for gelling capacity. 
crosslinking density. ${ }^{9,2}$ Remarkable increase in the viscosity of formulations from 64.8 to $259.2 \mathrm{cP}$ with the increase in the concentration of Carbopol $^{\circledR} 940$ from 0.3 to $0.8 \% \mathrm{w} / \mathrm{v}$. The same phenomena was observed with the formulations consisiting of $\mathrm{Carbopol}^{\circledR} / \mathrm{HPMC}$ polymeric mixture i.e. increase in the concentration of HPMC E4M from 0.6 to $2 \% \mathrm{w} / \mathrm{v}$ (F3 to F6) while maintaining the $\mathrm{Carbopol}^{\circledR} 940$ concentration constant at $0.8 \% \mathrm{w} / \mathrm{v}$. The similar findings was observed with Carbopol $^{\circledR} 934$ (0.6-0.8 \%w/v) and HPMC E4M $(1-2 \% \mathrm{w} / \mathrm{v})$ in formulations F7 to F10. The results are well in correlation with the Nanjwade et al. ${ }^{5}$ and Pandey et al..$^{30}$ where the researchers used a combination of Carbopol $^{\circledR}$ 934/HPMC E4M and Carbopol ${ }^{\circledR}$ 940/ HPMC E4M at various concentrations to formulate $\mathrm{pH}$ trggered in situ gels containing ketorolac tromethamine and levobunolol hydrochloride, respectively.

Formulations, F1 to F5 and F7 to F9 were found to be free flowing in nature. However, formulations F6 and F10 were not pourable in nature as they exhibited higher viscosity due to higher content of polymeric system. Hence, these two formulations were not considered for further studies.

\section{Gelling capacity}

An optimal in situ gelling formulation should have the balanced gelling capacity and viscosity which enables easy administration to the eyes with good gel formation by undergoing rapid sol to gel transition upon contact at the affected site. Besides, enhancing the residence time of drug at pre-corneal surface dependent on the viscosity of the formulations. ${ }^{31}$

Formulation F1 containing $0.3 \% \mathrm{w} / \mathrm{v}$ Carbopol $^{\circledR} 940$ and $0.6 \% \mathrm{w} / \mathrm{v}$ HPMC E4M was assigned with '-' sign as it is not having gelling ability at the $\mathrm{pH}$ of STF $(\mathrm{pH}$ 7.4) due to the low viscosity of solution and hence were abandoned for further studies. With increase in the concentration of Carbopol $^{\circledR}$ and HPMC, the formulations retained their liquid state at room temperature and at the formulated $\mathrm{pH}$ and increased the gelling capacity of the formulations upon exposure to $\mathrm{pH}$ of STF due to increase in the viscosity of formulations. Among all, formulation F5 demonstrated excellent gelling capacity and assigned with ' +++ ' sign. They formed stiff gel immediately and remained for extended period of time (more than 6-8 h).

The formation of stiffer gel might be due to hydrophobic nature of $\mathrm{Carbopol}^{\circledR}$ backbone and with increasing in the concentration, large amount of polymeric chains develop hydrophobic interchain aggregation. Also, due to increased ionization of functional groups present in Carbopol $^{\circledR}$ as a result of increasing $\mathrm{pH}$, leading to an increased replusion of negative charges along the polymer backbone and the subsequent expansion of polymeric network. Furthermore, by increasing the concentration of $\mathrm{Carbopol}^{\circledR} / \mathrm{HPMC}$ in the aqueous environment, they form a stable three dimensional viscoelastic network. ${ }^{32,33}$ The formulation of such in situ gels facilitates the sustained drug release locally by preserving their integrity without dissolving and eroding for prolonged period of time.

\section{In-vitro drug release studies}

The results of in-vitro drug release study was shown in Figure 1. The reference product released about $99.27 \%$ of drug within $2 \mathrm{~h}$. However, the selected formulations F3, F4 and F5 released 90\% of drug within 4, 6 and 8 h, respectively. These three formulations had same concentration of $\mathrm{Carbopol}^{\circledR} 940(0.8 \% \mathrm{w} / \mathrm{v})$ but the concentration of HPMC E4M as a viscosity enhancer increased from 0.6 to $1.5 \% \mathrm{w} / \mathrm{v}$. Similarly, the formulation $\mathrm{F} 8$ and $\mathrm{F} 9$ released $90 \%$ of drug within 3 and $4 \mathrm{~h}$, respectively. The formulation F8 and F9 contained same amount of $\mathrm{Carbopol}^{\circledR} 934(0.8 \% \mathrm{w} / \mathrm{v})$ but the concentration of HPMC E4M increased from 1 to $1.5 \% \mathrm{w} / \mathrm{v}$. Therefore, the in vitro drug release results demonstrated that higher viscosity with stronger gelling ablility plays an important role in sustaining the drug release from the formulations for prolonged period of time.

The $\mathrm{T}_{50 \%}$ of reference formulation (Albucid ${ }^{\circledR} 10 \%$ ), $\mathrm{F} 3$, F4, F5, F8 and F9 were $0.28,0.48,0.93,2.86,0.56$ and $0.76 \mathrm{~h}$, respectively. As the formulation F3 had an initial burst release at an initial hour, no statistically significant difference was observed between reference and F3. However, a statistically significant difference was observed

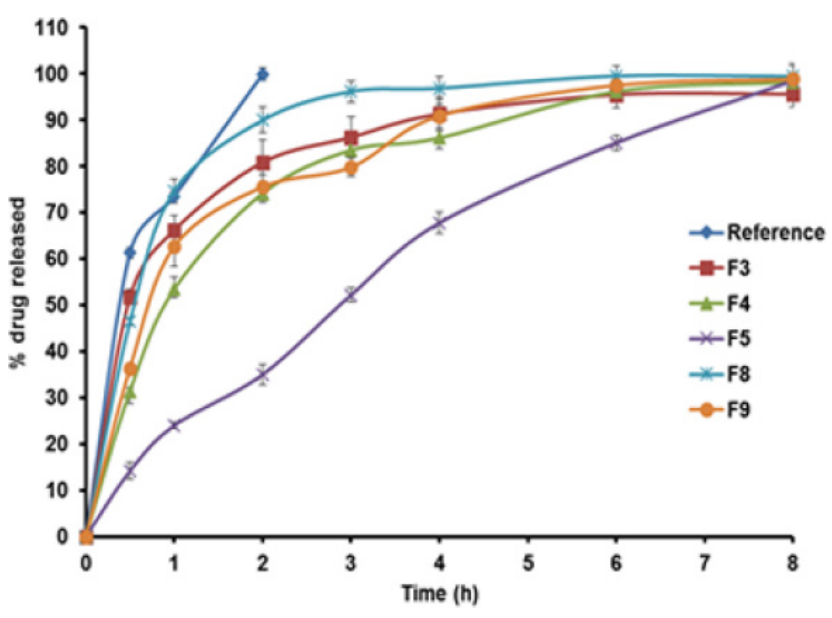

Figure 1: In-vitro release profile of sulfacetamide sodium from Reference (Albucid ${ }^{\circledR} 10 \%$ ), Carbopol ${ }^{\circledR 940 / H P M C ~ i n ~ s i t u ~}$ gels (F3: $0.8 / 0.6 \% \mathrm{w} / \mathrm{v}, \mathrm{F} 4: 0.8 / 1.0 \% \mathrm{w} / \mathrm{v}, \mathrm{F} 5: 0.8 / 1.5 \% \mathrm{w} / \mathrm{v}$ ) and Carbopol ${ }^{\circledR} 934 / \mathrm{HPMC}$ in situ gels (F8: 0.8/1.0\%w/v, F9: 0.8/1.5 $\% w / v)$. 
between reference, $\mathrm{F} 4$ and $\mathrm{F} 5$ as the initial burst release was decreased and exhibited sustained drug release with an increasing the concentration of HPMC E4M. The formulation F5 $(2.86 \mathrm{~h})$ had better sustained release profile compared to other in situ gel formulations and marketed eye drops. It could be due to the higher viscosity and excellent gelling capacity of the formulation which supported to immediate transition of solution to gel at ocular $\mathrm{pH}$ and remained in the gel form for a prologned period of time to sustain the sulfacetamide sodium release for $8 \mathrm{~h}$. This phenomenon eliminates the aforementioned disadvantages of eye drops i.e. rapid precorneal elimination of formulation caused by blinking of eyes and tear secretion and frequeuncy of dosing frequency of currently available sulfacetamide sodium eye drops (every 2-3 h). Therefore, the in situ gel formulation acheives the improved patient compinace and conveince with the dosing administration of every 8 h. Formulation F5 was selected as the best among the prepared formulations and evaluated for sterility testing and antimicrobial efficacy studies.

In order to find out the kinetic of drug release, the in-vitro drug release data was fitted into different release kinetic models. The best fit model of release pattern was considered with highest regression value $\left(r^{2}\right)$ of zero and first order. The regression values of Higuchi model which indicate diffusion mechanism and Hixon-crowell model which indicate erosion mechanism were compared to identify the release mechanism. The release mechanism can be further confirmed by the release exponent $(n)$ value in Korsemeyer-peppas model. The release kinetic results of in situ gels are presented in Table 3. The formulation F5 and conventional eye drops showed identical kinetic of drug release which was followed zero order release pattern and non-fickian diffusion (combination of diffusion and erosion) mechanism ( $n$ value was in between $0.43-0.85$ ).

\section{Sterility testing}

The results of the sterility test on the formulation F5 (Carbopol $^{\circledR}$ 940/HPMC-0.8/1.5 \%w/v) is shown in Figure 2. The results indicated that there is no evidence of microbial growth on the fluid thioglycolate medium during the incubation period of 14 days at $35^{\circ} \mathrm{C}$. Therefore, the formulation was found to be clear without appearance of turbidity which confirmed the steriltiy of formulation.

\section{Antimicrobial efficacy studies}

The zone of inhibition results from antimicrobial efficacy studies are shown in Table 4 and depicted in Figure 3. The zone of inhibition results demonstrated that

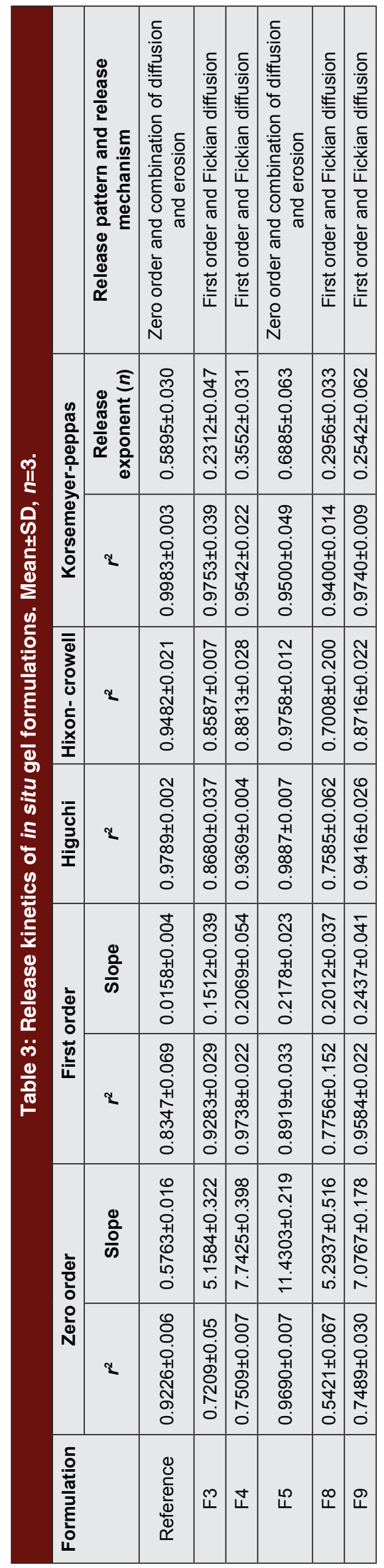




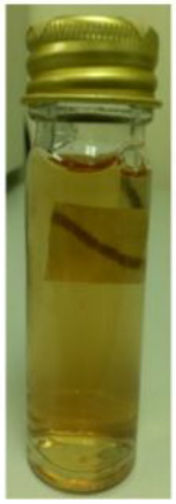

Day 0

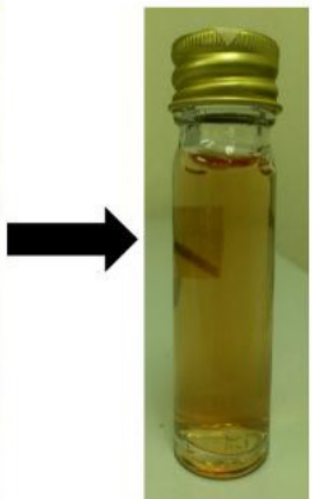

Day 7

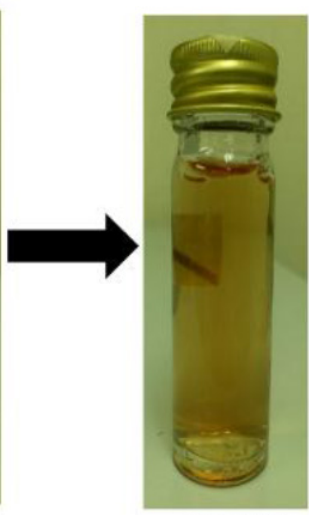

Day 14
Figure 2: Sterility testing of formulation F5 from 0 to 14 days.

\section{Table 4: Results of antimicrobial efficacy studies.}

\begin{tabular}{|c|c|c|}
\hline \multirow[b]{2}{*}{ Bacterial strains } & \multicolumn{2}{|c|}{ Zone of inhibition (mm), $n=3$} \\
\hline & $\begin{array}{c}\text { Reference } \\
\text { (Albucid }^{\circledR 10} \% \text { ) }\end{array}$ & F5 \\
\hline Stapylococcus aereus & $41.33 \pm 1.15$ & $39.67 \pm 1.53$ \\
\hline Escharichia coli & $41.33 \pm 1.15$ & $39.67 \pm 0.58$ \\
\hline Klebsiella pneumoniae & $35.00 \pm 1.00$ & $33.33 \pm 1.15$ \\
\hline
\end{tabular}

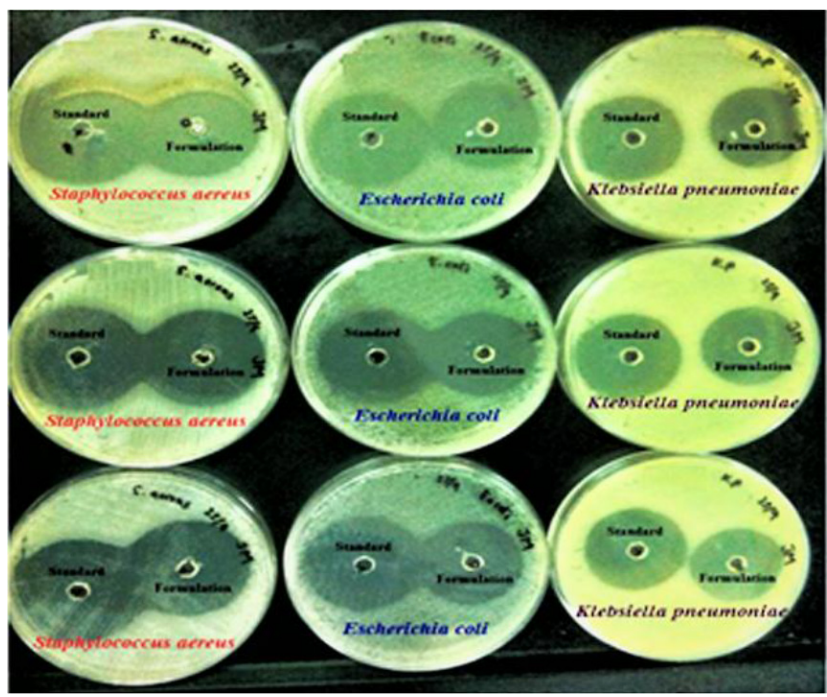

Figure 3: Antimicrobial efficacy: Zone of inhibition of Reference (Albucid ${ }^{\circledR}$ 10\%) and Formulation F5.

in situ gel formulation showed prominent antimicrobial efficiency against Staphylococcus aureus, Escherichia coli and Klabsiella pneumonia micro-organisms and the results were in comparable with the marketed product. It was statistically confirmed that there was no significant difference $(p>0.05)$ in antimicrobial activity of the marketed product and the selected formulation (F5) against the micro-organisms responsible for conjunctivitis and other superficial ocular infections. As described by
Pundir and Jain ${ }^{34}$ when the diameter of zone of inhibition is more than $18 \mathrm{~mm}$, it is considered that formulations have very active antimicrobial activity. Thus, it indicated that sulfacetamide sodium retained its very active antimicrobial efficiency even after being formulated in an in situ gelling system.

\section{CONCLUSION}

Sulfacetamide sodium was successfully formulated as $\mathrm{pH}$ dependent in situ ocular gel using $\mathrm{Carbopol}^{\circledR} /$ HPMC as a polymeric system. All the formulations were clear and free flowing solutions other than F6 and F10. The formulation F5 was found to be sterile and showed excellent gelling capacity. It also demonstrated a good viscosity and sustained the drug release over a period of $8 \mathrm{~h}$. The antimicrobial efficacy of selected formulation was similar to commercial eyes drops (Albucid $^{\circledR} 10 \%$ ). Therefore, it was concluded that in situ gelling formulation with Carbopol ${ }^{\circledR} / \mathrm{HPMC}$ would invariably improve the patient's compliance by minimising the frequency of drug administration and could be a viable alternative to the conventional commercial product.

\section{ACKNOWLEDGEMENT}

The authors would like to thank International Medical University, Kuala Lumpur, Malaysia for providing research grant (BP101301-95000) and facilities to carry out this study. Authors would like to thanks Dow Chemical Company, USA for providing HPMC as a gift sample.

\section{CONFLICT OF INTEREST}

The authors declare no conflict of interest.

\section{ABBREVIATIONS}

NaCl: Sodium chloride; STF: Simulated tear fluid; $\mathrm{NaHCO}_{3}$ : Sodium bicarbonate; HPMC: Hydroxypropyl methylcellulose; $\mathbf{C a C l}_{2} \cdot \mathbf{2} \mathbf{H}_{2} \mathbf{0}$ : Calcium chloride dihydrate.

\section{REFERENCES}

1. Agrawal AK, Das M, Jain S. In situ gel systems as 'smart' carrier for sustained ocular drug delivery. Expert Opin Drug Deliv. 2012;9(4):383-02.

2. Rajoria G, Gupta A. In situ gelling system: A novel approach for ocular drug delivery. Am J Pharmatech Res. 2012;2(4):24-53.

3. Rani TR, Mohit S. An insight to ophthalmic in situ gel: An overview. Int Res J Pharm. 2012;3(3):16-21.

4. Patil S, Kadam A, Bandgar S, Patil S. Formulation and evaluation of an in situ gel for ocular drug delivery of anticonjunctival drug. Cellulose Chem Technol. 2015;49(1):35-40. 
5. Nanjwade BK, Manjappa AS, Murthy RSP, Pol YD. A novel pH-triggered in situ gel for sustained ophthalmic delivery of ketorolac tromethamine. Asian J Pharm Sci. 2009;4(3):189-99.

6. Kant A, Reddy S, Shankraiah MM, Venkatesh JS, Nagesh C. In situ gelling system- An overview. Pharmacologyonline. 2011;2(1):28-44.

7. Kumar L, Singh PR, Singh SG, Kumar D. In situ gel: a novel system for ocular drug delivery. Int J Pharm Sci Rev Res. 2011;9(2):83-91.

8. Wu C, Qi H, Chen W, Huang C, Su C, Li W, et al. Preparation and evaluation of a Carbopol/HPMC-based in situ gelling ophthalmic system for puerarin. Yakugaku Zasshi. 2007;127(1):183-91.

9. Tinu TS, Thomas L, Anil KB. Polymers used in ophthalmic in situ gelling system. Int J Pharm Sci Rev Res. 2013;20(1):176-83.

10. Khare A, Grover K, Pawar P, Singh I. Mucoadhesive polymers for enhancing retention in ocular drug delivery: A critical review. Rev Adhesion Adhesives. 2014;2(4):467-02.

11. Srividya B, Cardoza RM, Amin PD. Sustained ophthalmic delivery of ofloxacin from a pH triggered in situ gelling system. J Control Release. 2001;73(23):205-11.

12. Al-Kassas RS, El-Khatib MM. Ophthalmic controlled release in situ gelling systems for ciprofloxacin based on polymeric carriers. Drug Del. 2009;16(3):145-52.

13. Deulker AL, Sancoalcar A, Vaidya S, Gude R. Formulation development and evaluation of long acting ophthalmic in-situ gelling system of dorzolamide hydrochloride. Int J Drug Dev Res. 2013;5(4):156-63.

14. USFDA: Inactive Ingredient Search for Approved Drug Products. [Cited 2018 May 1]. Available from: https://www.accessdata.fda.gov/scripts/cder/ iig/index.cfm.

15. Lubrizol Corporation. U.S. FDA approves generic drug product containing Lubrizol's Carbopol ${ }^{\circledR}$ polymer (Carbomer Homopolymer): Press release; 2012.

16. Dow Chemical Company. METHOCEL ${ }^{\mathrm{TM}}$ : World Class Leading Brand of HPMC. [Cited 2018 April 15]. Available from: https://www.dow.com/en-us/ pharma/products/methocel.

17. Charles FL, Lora LA, Morton PG, Leonard LL. Drug information handbook. Ohio: Lexi-Comp Inc; 2009.

18. Mohanambal E, Arun K, Hasan SA. Formulation and evaluation of $\mathrm{pH}-$ triggered in situ gelling system of levofloxacin. Ind J Pharm Edu Res. 2010;45(1):58-64.

19. El-Laithy HM, Nesseem DI, Shoukry. Evaluation of two in situ gelling systems for ocular delivery of moxifloxacin: In vitro and in vivo studies. J Chem Pharm Res. 2011;3(2):66-79.
20. Nayak NS, Sogali BS, Thakur RS. Formulation and evaluation of $\mathrm{pH}$ trigger in situ ophthalmic gel of moxifloxacin hydrochloride. Int J Pharm Pharm Sci. 2012;4(2):452-9.

21. Asasutjarit R, Thanasanchokpibnll S, Fuongfuchatc A, Veeranondha S. Optimization and evaluation of thermoresponsive diclofenac sodium ophthalmic in situ gels. Int J Pharm. 2011;411(1-2):128-35.

22. Kanoujia J, Sonker K, Pandey M, Kymonil MK, Saraf SA. Formulation and characterization of a novel pH-triggered in-situ gelling ocular system containing gatifloxacin. Int Current Pharm J. 2012;1(3):43-9.

23. Sun J, Zhou Z. A novel ocular delivery of brinzolamide based on gellan gum: in vitro and in vivo evaluation. Drug Des Devel Ther. 2018;12:383-9.

24. British Pharmacopoeia. Published on behalf of Medicines and Health care products Regulatory Agency; The department of Health, social services and public safety. Great Britain $6^{\text {th }}$ ed. 2010;2.

25. Indian Pharmacopoeia. The controller of publication, New Delhi; Ministry of health and family welfare. India. $6^{\text {th }}$ ed. 2010;2.

26. Narayanan AV, Rao BP. Development of an in situ gel forming solution for controlled ocular delivery of ciprofloxacin hydrochloride. Am J Pharmtech Res. 2013;3(3):791-806.

27. Gupta NV, Reddy GV. A Comparative study of quality control tests for eye preparations as per IP, BP and USP. Int J Drug Dev Res. 2015;7(1):61-8.

28. Madan M, Bajaj A, Lewis S, Udupa N, Baig JA. In situ forming polymeric drug delivery systems. Indian J Pharm Sci. 2009;71(3):242-51.

29. Kushwaha SKS, Saxena P, Rai AK. Stimuli sensitive hydrogels for ophthalmic drug delivery: A review. Int J Pharm Investig. 2012;2(2):54-60.

30. Pandey A, Mali PY, Sachdeva D, Patel DK, Ramesh R. Development and optimization of levobunolol hydrochloride in-situ gel for glaucoma treatment. Int J Pharm Biol Arch. 2010;1(2):134-9.

31. Jain D, Kumar V, Singh S, Mullertz A, Bar-Shalom D. Newer trends in in situ gelling systems for controlled ocular drug delivery. J Anal Pharm Res. 2016;2(3):22-38.

32. Choy Y, Park J, McCarev B, Edelhauser HF, Prausnitz M. Mucoadhesive microdiscs engineered for ophthalmic drug delivery: Effect of particle geometry and formulation on precorneal residence time. Invest Ophthalmol Vis Sci. 2008;49(11):4808-15.

33. Upadhayay P, Kumar M, Pathak K. Norfloxacin loaded $\mathrm{pH}$ triggered nanoparticulate in-situ gel for extraocular bacterial infections: Optimization, ocular irritancy and corneal toxicity. Iran J Pharm Res. 2016;15(1):3-22.

34. Pundir RK, Jain P. Comparative studies on the antimicrobial activity of black pepper (Piper nigrum) and turmeric (Curcuma longa) extracts. Int J App Biol Pharma Technol. 2010;1(2):492-01.

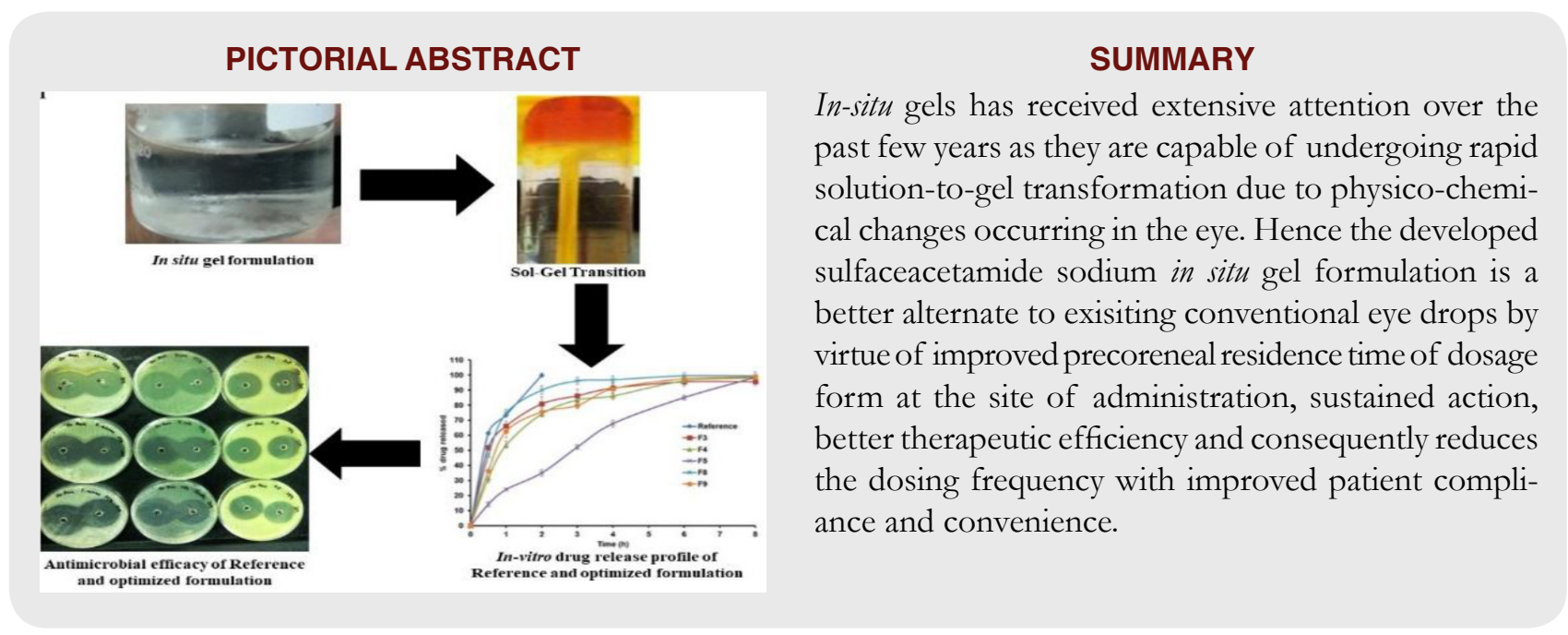




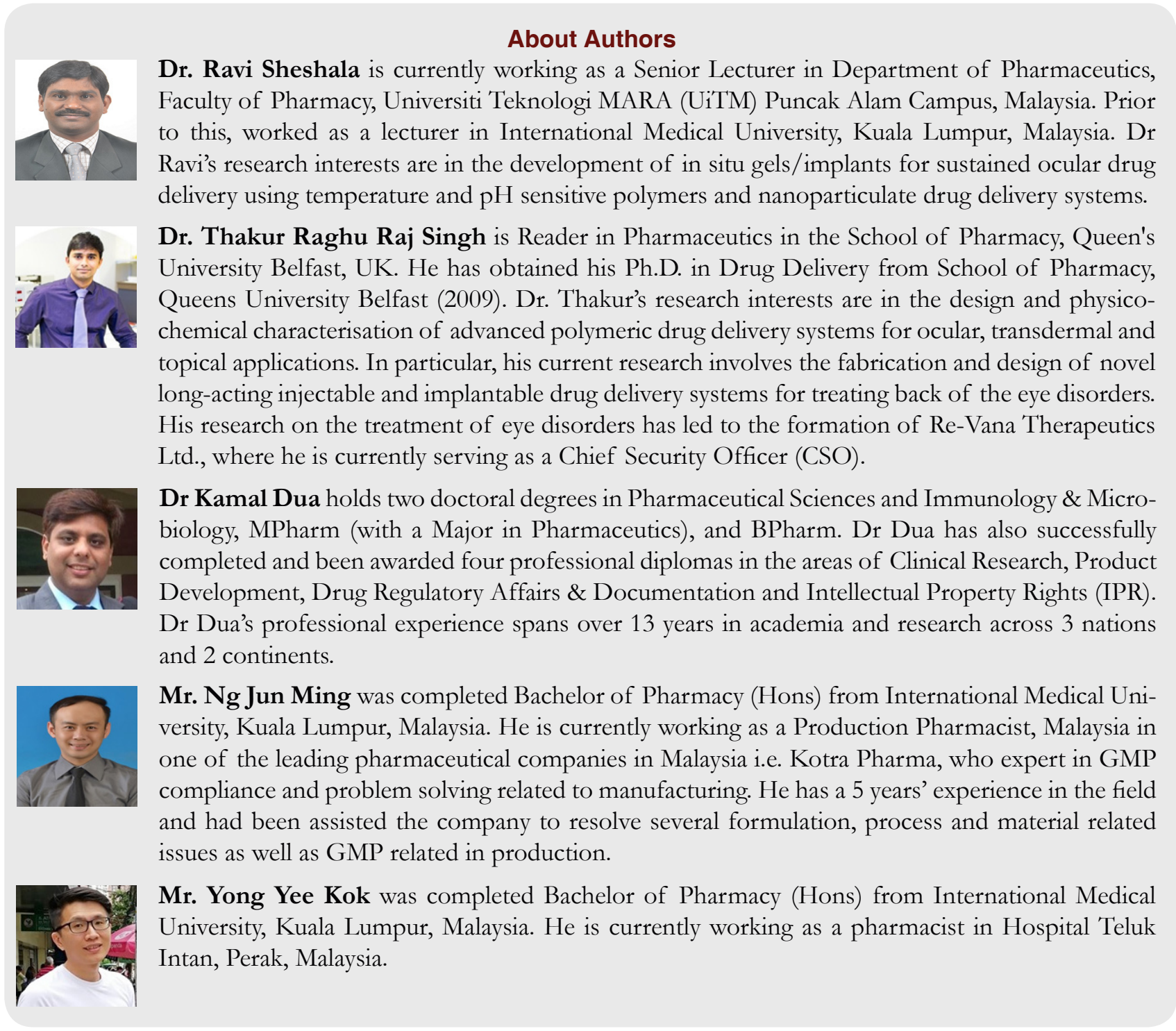

Cite this article: Sheshala R, Ming NJ, Kok YY, Singh TRR, Dua K. Formulation and Characterization of pH Induced in situ Gels Containing Sulfacetamide Sodium for Ocular Drug Delivery: A Combination of Carbopol ${ }^{\circledR} / \mathrm{HPMC}$ Polymer. Indian J of Pharmaceutical Education and Research. 2019;53(4):654-62. 